\title{
INVESTIGATION OF FLANK WEAR WHEN FINISH TURNING OF High STRENGTH STEEL WITH CBN CUTTING INSERT
}

\author{
Jozef Majerík, Igor Barényi \& Josef Sedlák
}
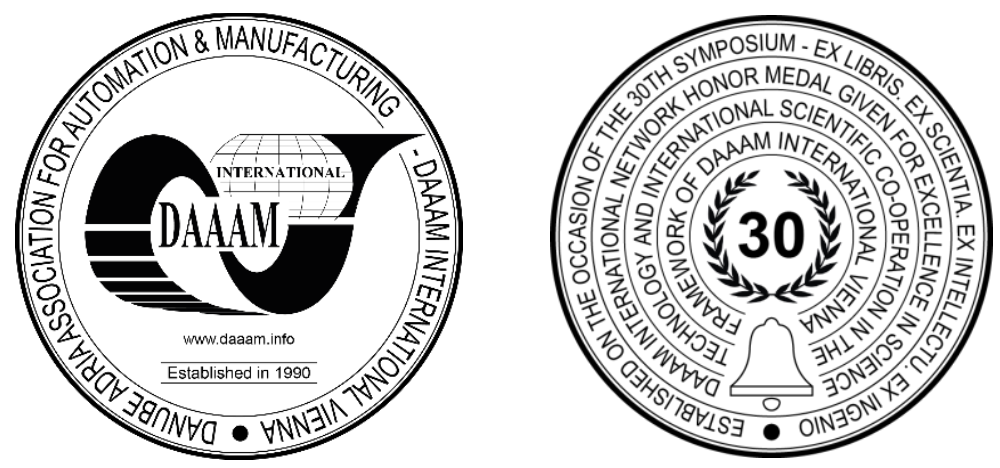

This Publication has to be referred as: Majerik, J[ozef]; Barenyi, I[gor] \& Sedlak, J[osef] (2019). Investigation of Flank Wear when Finish Turning of High Strength Steel with CBN Cutting Insert, Proceedings of the 30th DAAAM International Symposium, pp.0215-0222, B. Katalinic (Ed.), Published by DAAAM International, ISBN 978-3-90273422-8, ISSN 1726-9679, Vienna, Austria

DOI: $10.2507 / 30$ th.daaam.proceedings.028

\begin{abstract}
The article of authors is concentrated to an analysis of the certain topics connected with the process of finish turning, which are: finishing as a technological process, purpose-built machining, tool wear and tool life of cutting materials, criteria of flank wear, measuring methods of wearing of the cutting tools, types of the cutting materials and their using in the common practise. In the theoretical part of this article, there are results of different studies published, for which the goal was to review the dependency of cutting parameters on the tool life of the cutting material, comparison of the flank wear of stated cutting materials during certain cutting parameters of the process, analysing of the results of experiments oriented to tool life of cutting materials. In practical part, there is the description of particular parts connected with the own performed experiments, for which the aim was to determine the proper cutting parameters for the process of finish turning of hardened material by the hard-cutting material on the base of polycrystalline cubical boron nitride, evaluation and analysis of the results, determination of the conclusions from performed experiments and particular recommendations for the effective using of investigated cutting material.
\end{abstract}

Keywords: hard finish turning; cutting speed; flank wear; cubical boron nitride.

\section{Introduction}

Tool wear is a common part of all machine elements that are in contact with each other and in relative movement. In machining, the interaction of the cutting edge with the workpiece interactions, resulting in the separation of a portion of the material from the workpiece in the form of a chip of different shapes and sizes, and including microparticles of the cutting material of the tool (face and flank area of cutting insert). Of course, this interaction leads to wear of the cutting tool over time [1], [2].

Several collectives of authors [3], [5], [7], [8], [9], [10] performed investigations and measurements of flank wear during hard finish turning process with $\mathrm{CBN}$ changeable cutting inserts and publish all results in articles. 
The process of wear is a very complex process, which depends on many interacting factors (physical and especially mechanical properties of the machined and tool material, type of machining operation, tool geometry, cutting conditions, cutting zone, etc.) and many different physico-chemical activities phenomena (wear mechanism) [2], [6], [11].

Abrasion and adhesion are also often referred to in the technical literature as physical mechanisms of wear, diffusion and oxidation as chemical, all of which wear continuously over time, with the point in time when they start to act may not always be the same. Plastic deformation and brittle fracture, on the other hand, are mechanisms that act suddenly, at some point, and usually cause an immediate termination of the tool's functionality (sudden change of the tool's cutting edge shape, avalanche wear or cutting insert peeling) [1], [3]. Flank area of cutting insert wear mainly due to abrasion and oxidation. On the other side, face area of cutting insert wear due to adhesion, diffusion, abrasion and oxidation.

Various experiments have shown that the cutting edge is worn mainly on the flank and face of the tool insert, or at the tip thereof, and the size of the individual wear depends on the contribution of certain co-operating factors of the cutting process, e.g. tool geometry, type of operation (roughing, finishing) and last but not least cutting conditions (cutting speed, feed rate, cutting edge width, cutting zone) [4], [5].

Determination of individual wear criteria on the front and back of the cutting wedge of the tool is used in technical practice, but it slightly deviates to the method of marking wear according to STN ISO 3685 standard, which identifies the individual criteria as follows:: $V C$ as $V B C, V B$ as $V B B, V B_{\max }$ as $V B B_{\max }$ and $V N$ as $V B N$ [1], [3].

\section{Experimental work}

The measurement of the selected wear criterion is most commonly used in technical practice as the wear criterion of the $V B$ and $K T$ values or the tool wear value of the $V C$ and $K V Y$. The most commonly used criterion for determining the guaranteed life of a cutting insert is the wear of the cutting edge on its main back, indicated by $V B$, which is actually the length parameter (perpendicular to the plane of the face) of the newly formed surface.

This wear has a great effect on heat generation during the cutting process and also on final roughness of the resulting surface after the machining process. This working surface of the tool is in contact with the machined surface all the time, and thus diffusion processes can occur on the surfaces of both materials, thereby influencing the composition in the surface layers of both the cutting and the machined material. $V B$ values are measured using a light workshop microscope. To determine the wear value, first set the crosshair line of the microscope to a position where the line follows the contour of the cutting tool edge, and then move the line to the position where it overlaps with the maximum value of the measured criterion. In this way, the individual wear criteria are subtracted.

\section{Materials and methods}

Cubical boron nitride is currently also frequently used as a cutting material for finishing operations on hardened or very hard workpiece materials (with a hardness higher than $45 \mathrm{HRC}$ ). The advantage of such a finishing process is that it can replace finishing operations by grinding without the product having to be moved to the grinding machines for its final finishing operations (it still remains clamped in the machining centre where all previous operations have been performed). A correctly set finishing process for turning hard materials with a CBN cutting insert can ensure a surface roughness below $\mathrm{Ra}=0.8 \mathrm{~mm}$. Another advantage of this crystalline cutting material is that it does not require the use of cutting fluids in the machining process since it has a stable structure even at high temperatures. To better understand the use of CBN-based cutting material, an experiment was conducted to determine the most appropriate cutting speed for finishing operations. These values were determined from the recommended values by the process users - grinding replacement by turning operations using CBN cutting material.

The cutting material used in the experiment process is of the YCB 131 type (microstructure can be seen in Fig. 1a) and has the production designation of ZCC Cutting Tools Europe GmbH for one of three types of cutting materials manufactured on the basis of $\mathrm{CBN}$, which has high hardness, long tool life. and excellent heat resistance at high temperatures $\left(1300{ }^{\circ} \mathrm{C}\right)$. This material is suitable for machining hardened steel $(55-63 \mathrm{HRC})$, bearing steel, tool steel (HSS grade at low feed rates), steel castings, ductile cast iron, grey cast iron, hard cast iron (high percentage of alloys such as $\mathrm{Ni}, \mathrm{Co}$ and $\mathrm{Cr}$ ) and super alloys. The cutting material has a fine-grained texture (the finest in its category), which reduces its susceptibility to brittle fracture and increases toughness and is therefore also suitable for interrupted cuts.

Cutting insert with geometry designation type WNGA 080408S020020-3 (see Fig. 1b) made of cutting material CBN type YCB 131 is designed for finishing operations of hard materials such as e.g. hardened steels or various types of alloys. It is made of tool steel on which special tips made of CBN material are attached (this joint must withstand high pressures and temperatures). The great practicality of such a design is not only the lower cost of the interchangeable cutting insert, but above all the tougher base under the cutting tip, which can absorb more shaking, thereby extending the stability of the CBN structure. Since the wedge of such a cutting insert must be supported under its entire surface in the cutting insert holder, such cutting plates are not produced with cutting tips on both sides when the tip is worn, this tip could not provide a solid transfer of cutting forces from the process cutting into a replaceable cutting plate holder, which would ultimately prove to be a loss of the tip durability on the opposite side of the insert. 

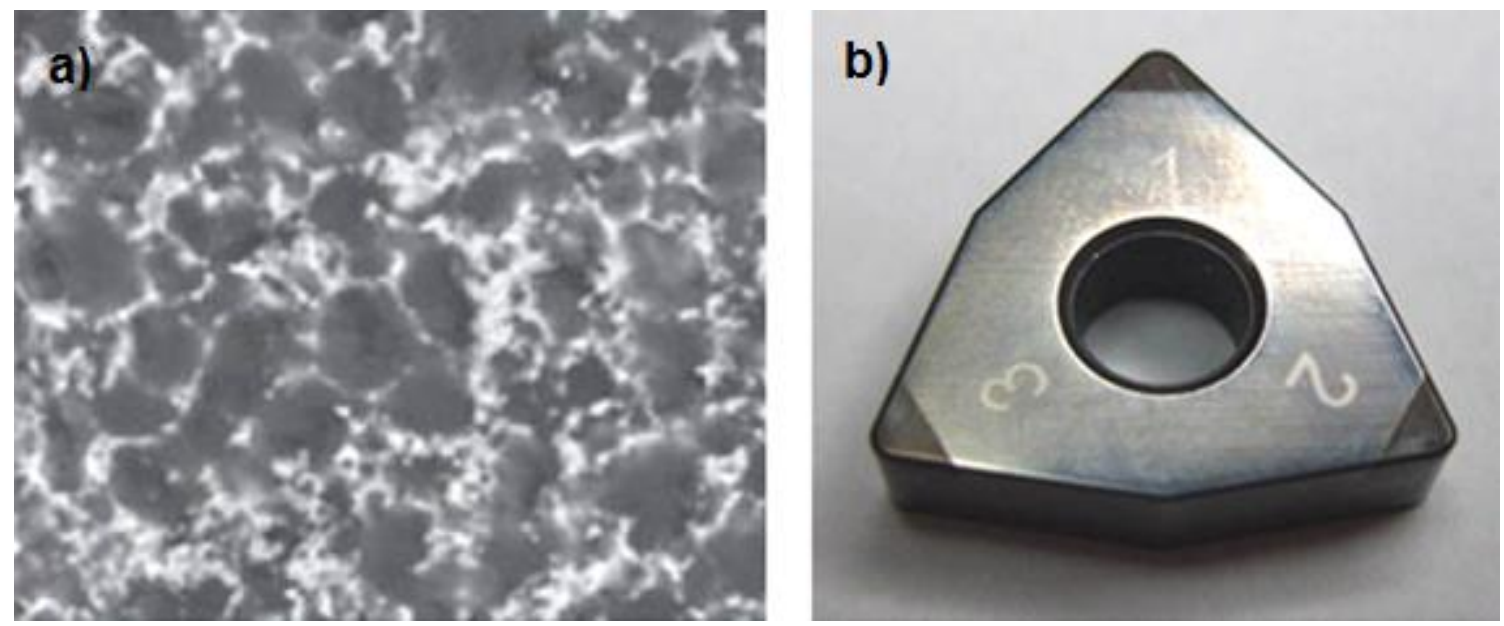

Fig. 1. a) Microstructure of cutting material CBN type YCB 131, b) WNGA 080408S020020-3 geometry of cutting insert used in performed experiments

The workpiece material with high strength and after hardening also hardness was designed for the realized cutting speed selection experiment as an indicator of the durability of the CBN interchangeable cutting insert, namely steel with the product designation BÖHLER K600. It is a steel that can be used for cold work with high toughness and hardenability, even hardness even at larger cross-sections. The BÖHLER K600 steel is characterized by:

- high impact strength and compressive strength,

- $\quad$ possibility of oil and air hardening,

- $\quad$ good polishability.

BÖHLER K600 steel can also be delivered from the new production in ISODUR quality e.g. in ESU quality. The chemical composition of the steel is given in Table 1 and its mechanical properties are given in Table 2 .

\begin{tabular}{|c|c|c|c|c|c|c|}
\hline Chemical composition & $\mathrm{C}$ & $\mathrm{Si}$ & $\mathrm{Mn}$ & $\mathrm{Cr}$ & Mo & $\mathrm{Ni}$ \\
\hline Content in \% & 0,48 & 0,23 & 0,40 & 1,30 & 0,25 & 4,00 \\
\hline Standards & \multicolumn{5}{c|}{ DIN / EN < 1.2767 >, 45NiCrMo16, AISI -, STN 19 655 } \\
\hline Delivery status & \multicolumn{5}{c|}{ Soft annealed max. 285HB/30HRC } \\
\hline
\end{tabular}

Table 1. Chemical composition of BÖHLER K600 steel

\begin{tabular}{|c|c|c|c|c|c|}
\hline Physical property at temperature $20^{\circ} \mathrm{C}$ & \multicolumn{3}{|c|}{ Value } & \multicolumn{2}{|c|}{ Unit } \\
\hline Density & \multicolumn{3}{|c|}{7,85} & \multicolumn{2}{|c|}{ kg.dm ${ }^{-3}$} \\
\hline Thermal conductivity & \multicolumn{3}{|c|}{28,0} & \multicolumn{2}{|c|}{$\mathrm{W} /(\mathrm{m} . \mathrm{K})$} \\
\hline Specific heat capacity & \multicolumn{3}{|c|}{460} & \multicolumn{2}{|c|}{$\mathrm{J} /(\mathrm{kg} . \mathrm{K})$} \\
\hline Specific electrical resistance & \multicolumn{3}{|c|}{0,30} & \multicolumn{2}{|c|}{ Ohm.mm2.m $\mathrm{m}^{-1}$} \\
\hline Modulus of elasticity & \multicolumn{3}{|c|}{$210 \times 10^{3}$} & \multicolumn{2}{|c|}{ N.mm ${ }^{-2}$} \\
\hline $\begin{array}{c}\text { Physical properties between } 20\left[{ }^{\circ} \mathrm{C}\right] \text { and } \\
\ldots\left[{ }^{\circ} \mathrm{C}\right]\end{array}$ & 100 & 200 & 300 & 400 & 500 \\
\hline Thermal expansion $\left[10^{-6} \mathrm{~m} / \mathrm{m} \cdot \mathrm{K}\right]$ & 11.0 & 12.5 & 13.0 & 13.5 & 14.0 \\
\hline
\end{tabular}

Table 2. Mechanical properties of BÖHLER K600 steel

\begin{tabular}{|c|c|c|c|c|}
\hline Experiment No. & $\begin{array}{c}\text { Type of cutting } \\
\text { material }\end{array}$ & $\begin{array}{c}\text { Cutting speed } \boldsymbol{v}_{\boldsymbol{c}} \\
\left(\mathbf{m . m i n}^{-\mathbf{1}}\right)\end{array}$ & $\begin{array}{c}\text { Feed rate per } \\
\text { revolution } \boldsymbol{f} \\
\left(\mathbf{m m . r e v}^{-1}\right)\end{array}$ & Width of cut $\boldsymbol{a}_{\boldsymbol{p}}(\mathbf{m m})$ \\
\hline 1. & YCB 131 & 80 & 0,05 & 0,1 \\
\hline 2. & YCB 131 & 95 & 0,05 & 0,1 \\
\hline 3. & YCB 131 & 110 & 0,05 & 0,1 \\
\hline
\end{tabular}

Table 3. Cutting parameters of turned BÖHLER K600 steel with YCB 131cutting material 

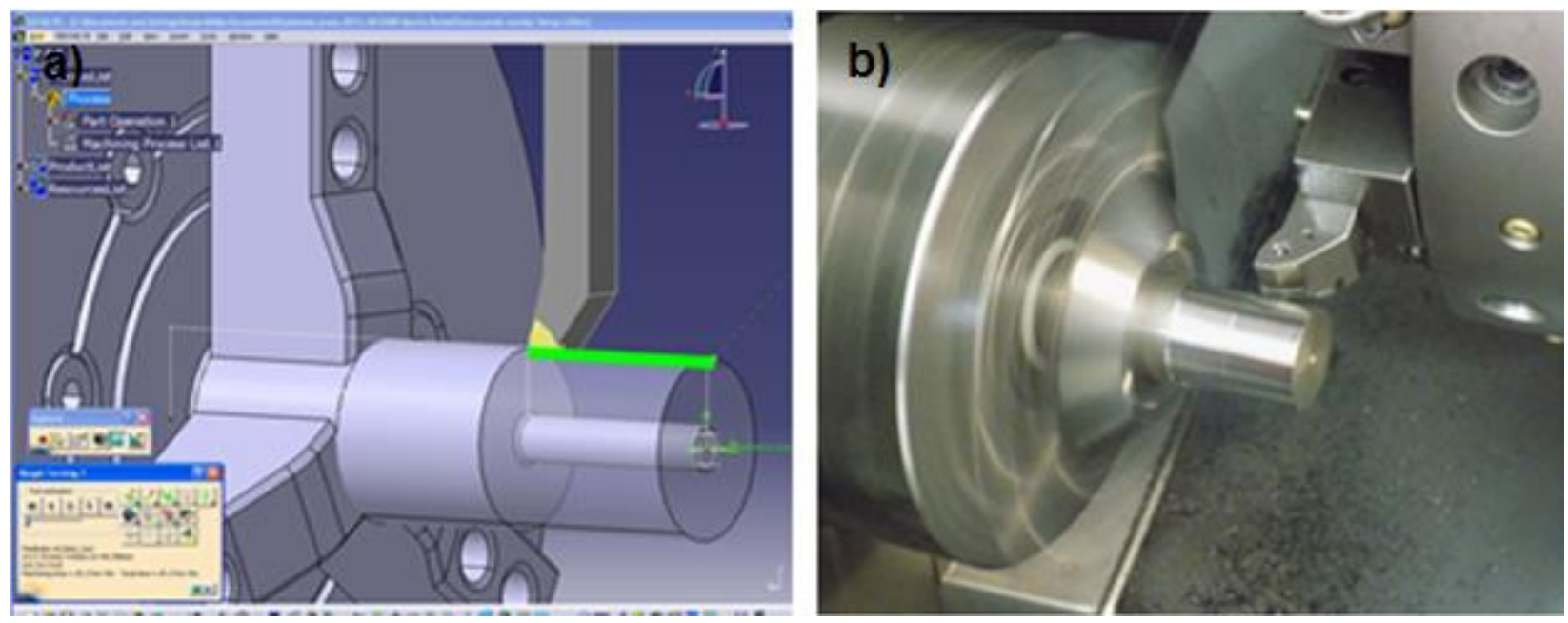

Fig. 2. a) Simulation of the turning process in the CATIA V5 system, b) turning process of BÖHLER K600 steel

The workpiece material for the experiment process was designed and manufactured according to the requirement exposed to a $300 \mathrm{~mm}$ steel rod, circular cross-section sample, hardened in a vacuum furnace to a surface hardness of 55.1 - 55.9 HRC and subsequently turned to a diameter of $40 \mathrm{~mm}$.

The HAAS SL20HE CNC lathe machine was used as an indicator of performed tool life with CBN cutting inserts. It is a computer-controlled machining process, where it is necessary to load the required NC program into the device (what we want to work with, what cutting parameters) and select a starting point for its coordinate system, but also with the possibility of manually controlled machining process. The lathe parameters are a specific indicator of its possible use. The HAAS SL20HE lathe machine met the requirements for longitudinal turning of a steel bar with CBN cutting insert according to predetermined cutting parameters. An important parameter needed for such a process is its stiffness and dimensional accuracy.

For this experiment, all cutting parameters within the range recommended by the manufacturer of this cutting material have been determined and specific values have been defined following the recommendation of users of such cutting materials in practice. The values were chosen for finishing machining operations performed on a lathe with the greatest possible cutting performance. This process was carried out without the use of cutting fluids. dry machining process. Table 3 shows all three variations of the combination of cutting parameters of the experiment that were realized.

The whole realized experiment was based on continuous monitoring of the wear of the main back part of the cutting edge, thus $V B$ value at periodic time intervals, which were read from the cutting insert every four consecutive cuts of the cutting wedge. As the cutting speeds varied, this cycle time (four shots) was different, from 4 min and 8 seconds at cutting speed of $110 \mathrm{~m} \cdot \mathrm{min}^{-1}$ up to $6 \mathrm{~min}$ at cutting speed of $80 \mathrm{~m} \cdot \mathrm{min}^{-1}$. This machining cycle in the form of a program (see Fig. 2a) was carried out in the CATIA V5 system before the experiment.

Reading of the wear value from the main back surface was performed using an optical measuring instrument called Brinell Magnifier. It is a specially modified magnifying glass, which is equipped with a metric scale from $0.1 \mathrm{~mm}$ to the most sensitive $0.01 \mathrm{~mm}$ in the field of view of the magnified image. However, such a method of measurement is always burdened by an incorrect reading of the value from the back of the cutting edge and therefore the reading was always performed by two persons and, if the results did not match, the measurement was performed until the results of the reading matched. Only then was the measurement recorded and the experiment continued until the $V B$ criterion $=0.3 \mathrm{~mm}$ was reached. The fact that a $V B$ value of $0.3 \mathrm{~mm}$ was reached ended the defined cutting speed test and continued the experiment with the next defined cutting speed and the new cutting edge.

As mentioned in the article, the basis for efficient use of CBN-based cutting material is not only the choice of the right cutting parameters, but also the rigidity of the entire technological system. To ensure the rigidity of the tool and workpiece in the cutting process during the experiment and to eliminate as much resonance vibration generated by the interaction of the hard workpiece with the hard cutting material, the ejection of the cutting holder in the clamping head and the ejection of the workpiece measures, which can also be seen in Figure $2 b$.

\section{Results and discussion}

In the first part of the realized experiment, a YCB 131 type of CBN cutting insert was tested at a cutting speed of 80 m. $\min ^{-1}$ (see Fig. 3). This value was recommended by CBN users for turning finishing operations as the lower cutting speed limit.

After commencing the machining process of the investigated steel, it was noted that the chip was integrally formed with a short interruption. The machining process was accompanied by a very gentle shaking of the technological system, and occasionally the chip was heated (sparking) as a result of the chip being caught on the workpiece, which later reached the cutting point where its interruption was accompanied by the aforementioned phenomenon. During the reading of the 
wear from the cutting edge, the roughness of the machined surface and thus the quality of the machined surface were also evaluated (although not exactly). With the passage of time, due to blunting of the cutting edge, more frequent interruption of the chip has occurred and also a slight deterioration of the surface roughness. The first part of the experiment was completed at time $t=33 \mathrm{~min}$, when the amount of wear on the main back was $V B=0.3 \mathrm{~mm}$. The cutting edge was worn by typical abrasive wear, but there was no destruction or breakage of the cutting material from the edge.

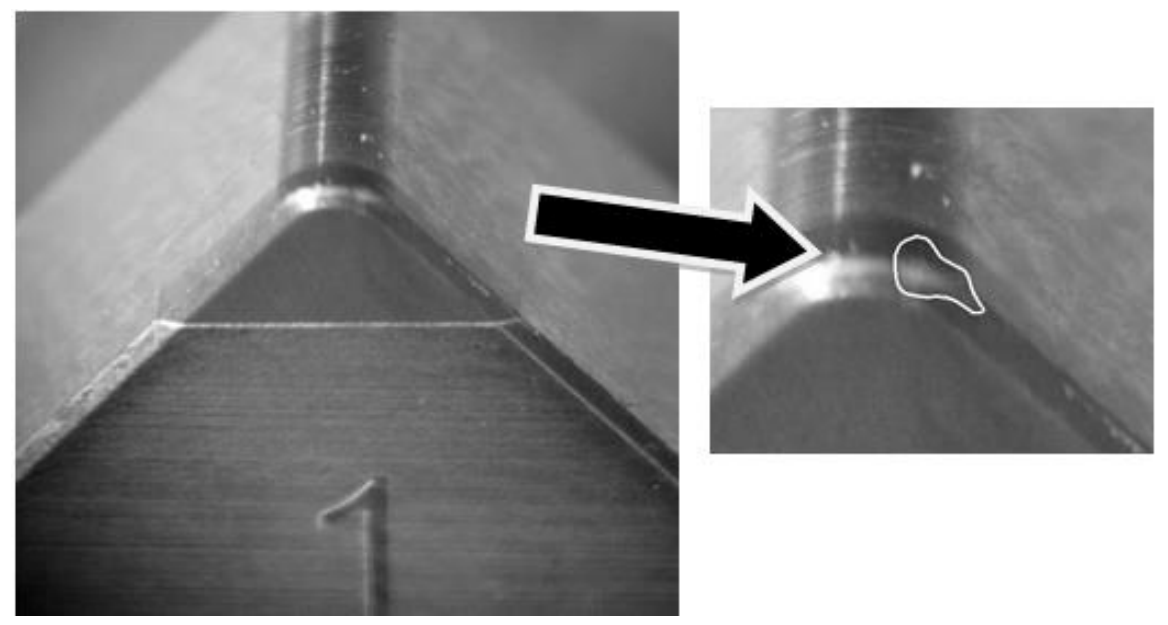

Fig. 3. Wear range on CBN cutting insert of type YCB 131 using cutting speed $v_{c}=80 \mathrm{~m} \cdot \mathrm{min}^{-1}$

In the second part of the experiment, a CBN cutting insert of YCB 131 type was also tested but at a cutting speed of value $95 \mathrm{~m} \cdot \mathrm{min}^{-1}$ (see Fig. 4). This value was determined as the mean of the cutting speed limit values set by CBN users for turning finishing operations.

After machining of the investigated steel, it was noted that the chip (as in the first part of the experiment) was integral with a very short interruption, but more often the chip was trapped on the workpiece. The vibrations during the machining process had a lower noise intensity than in the first case, and the chips were also burned (sparks). The surface roughness was also examined during subtraction of wear from the cutting edge, but the difference between the remaining surface in this part of the experiment was slight compared to the surface from the previous part of the experiment, so it can be said that the surface roughness was similar if not identical.

At a time of approx. $15 \mathrm{~min}$, due to the gradual blunting of the cutting edge (a very small radius occurred), more frequent chip breaking and also a slight deterioration of the surface roughness (still the same affinity as in the first part of the experiment). The second part of the experiment was completed in 34 min and 50 seconds, when the amount of wear on the main back part was $0.31 \mathrm{~mm}$.

The cutting edge was worn by abrasive wear, which was on the wider part of the cutting edge in comparison to the wear in the previous part of the experiment. Even in this case, the cutting material did not break and break out of the cutting edge.

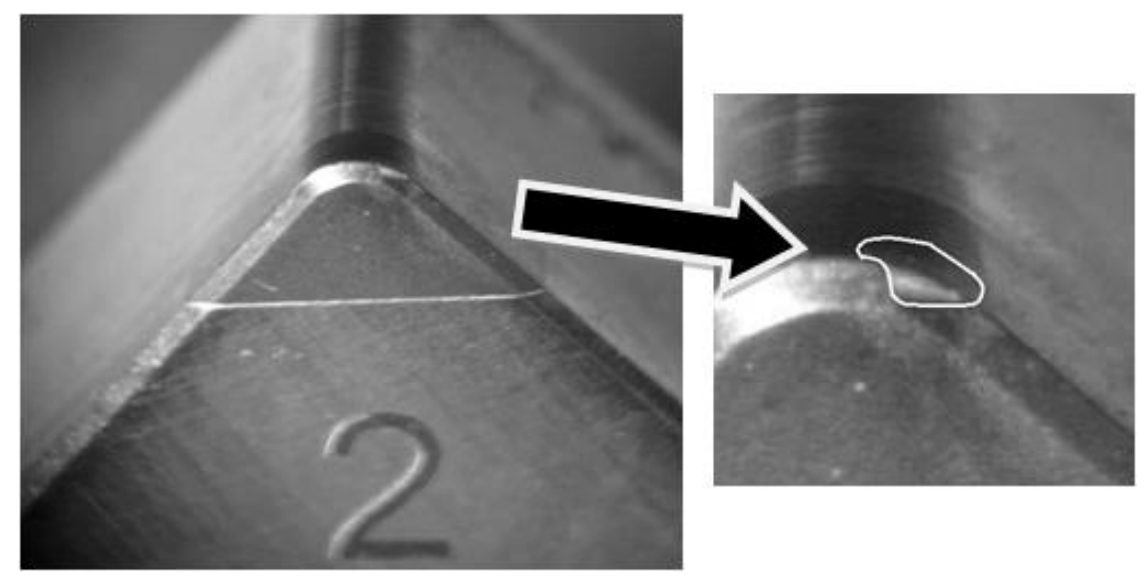

Fig. 4. Wear range on CBN cutting insert of type YCB 131 using cutting speed $v_{c}=95 \mathrm{~m} \cdot \mathrm{min}^{-1}$

In the last (third) part of the experiment, the YCB 131 cutting insert was also tested but at a cutting speed of 110 m. $\min ^{-1}$ (see Fig. 5). This was the upper limit value recommended by CBN users for turning finishing operations. 
The beginning of the last part of the experiment of machining the investigated steel was accompanied, as in the previous formation of a continuous chip, which in the form of a helix separated and fell into the lathe catch point. It was only sporadically captured on the workpiece, which then caused its uncontrolled flying away from the cutting point until the cutting wedge was stopped. Due to the higher cutting speeds and hence the turning speed, the machining process was considerably quieter (the process resonances had a quieter nature) and the metal sparking did not accompany the machining process. In the first three readings of wear from the wedge, the surface roughness was found to be lower than in the previous two parts of the experiment.

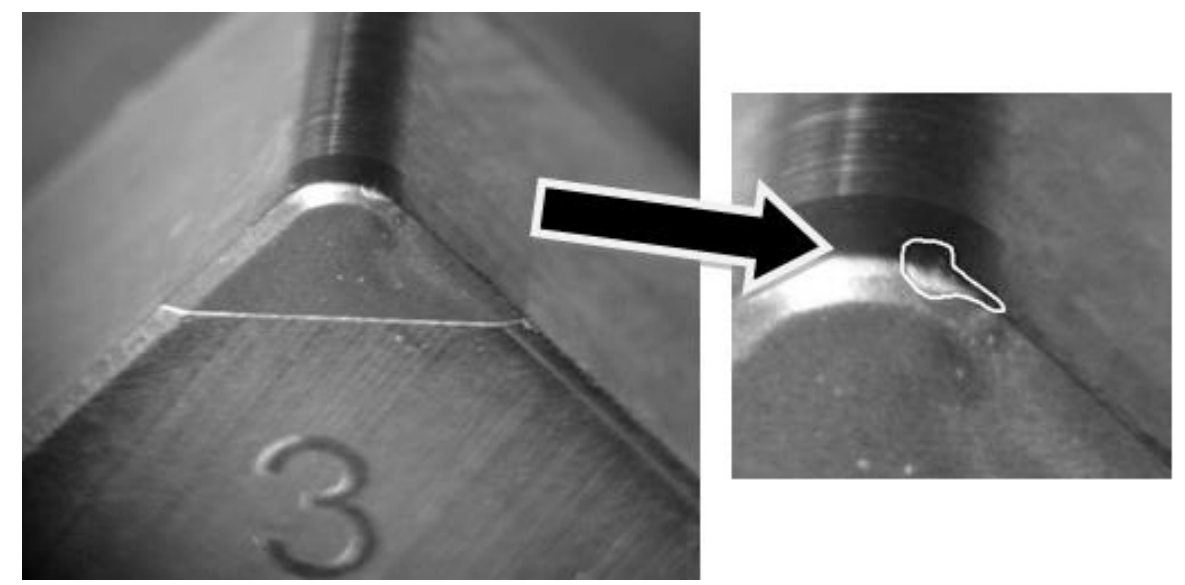

Fig. 5. Wear range on CBN cutting insert of type YCB 131 using cutting speed $v_{c}=110 \mathrm{~m} . \mathrm{min}^{-1}$

At the beginning of the third part of the experiment with the upper limit cutting speed, faster wear of the cutting edge on the main back of the changeable cutting insert was registered, but this stabilized later (after approx. 6 min.) And the rise in $V B$ slowed. The end time at which the $V B B$ criterion was reached was set at 21 minutes and 10 seconds when the $V B$ wear was $0.31 \mathrm{~mm}$. Like the values from the previous sections, they were recorded and later statistically processed. Wear of the cutting wedge was accompanied, as in the second part of the experiment, by more extensive abrasive wear of the cutting edge, not only on its back surface, but also partly on the front surface of the cutting wedge. On the cutting wedge you can see a continuous part of longitudinal wear $V B$, but also a certain part with a higher value of wear on the back part of the so-called. $V B B$. When comparing the results of the individual parts of the experiment, several aspects related to the process of machining hard materials using a $\mathrm{CBN}$-based cutting material during the duration of the experiment as well as the quality of the machined surface were considered.

The graph (see Fig. 6) shows the individual flank wear / time dependence at certain (defined) cutting speed in the form of curves. Each of the curves has its own character, and the processes taking place in the cutting materials during the interaction between the cutting edge and the workpiece can also be determined from the dependence recorded in the individual curves. Since abrasive wear was the dominant wear of the cutting wedge during machining, the other influences that influenced the process during machining could be partially neglected when assessing dependency. From the so-called "steepness" of the individual curves, it can be concluded that the structural bonds in the cutting material during machining at different cutting speeds were different, manifested by their resistance to abrasive wear, especially on the main back of the cutting wedge. An important factor of the durability of the cutting edge is its continuous wear and tear with time by curvature, this indicates that the surface intercrystalline bonds of the cutting material weaken and the structure loses strength.

Taking into account these facts, the most advantageous dependence of the cutting edge flank wear versus time at a cutting speed of $95 \mathrm{~m} \cdot \mathrm{min}^{-1}$, since the wear values had a smooth slight increase and no indications were visible on the cutting tip surface after exceeding the $V B B$ criterion of $0.3 \mathrm{~mm}$ destructive wear, that is to say the cutting material has steadily worn. The lower value of the cutting edge flank wear with time at $110 \mathrm{~m} \cdot \mathrm{min}^{-1}$ was attributed to higher cutting force values due to higher workpiece revolutions which, when cutting edge into the workpiece, caused greater resistance to the hard workpiece in the cutting edge. The external manifestation of this resistance was an increase in the speed of flank wear of the cutting edge by abrasive wear caused by the hard structure of the workpiece. The dependence of cutting edge durability on time at cutting speed of $80 \mathrm{~m} \cdot \mathrm{min}^{-1}$ was stable and there was no step change, but the final wear phase, unlike the cutting edge flank wear versus time at a cutting speed of $95 \mathrm{~m} . \mathrm{min}^{-1}$, tended to rise sharply, be caused by the gradual weakening of the intercrystalline bonds, thus increasing the loss of strength of the cutting material, even though no destructive signs were visible at the end of the experiment at the cutting wedge surface and the cutting edge width was lowest among all three parts of the experiment.

The evaluation of the differences in wear at different cutting speeds by chip formation was difficult to identify, since in all three parts of the experiment, until the end of the experiment, a relatively solid, slightly continuous chip with the same colour induced by the cutting temperature was formed. The study of the size and location of the flank wear in worn cutting insert was also monitored with the usage of the Scanning Electron Microscopy SEM (see Fig. 7a, b). SEM was utilized to evaluate worn cutting inserts, for high appearance of the worn shape and size of flank wear. This analysis has 
allowed investigate the flank wear effects that describe the overall tool wear. Crater wear (see Fig. 7b) is obvious on the tool rake face and is especially involved by the high machining temperature on cutting insert-chip landmark.

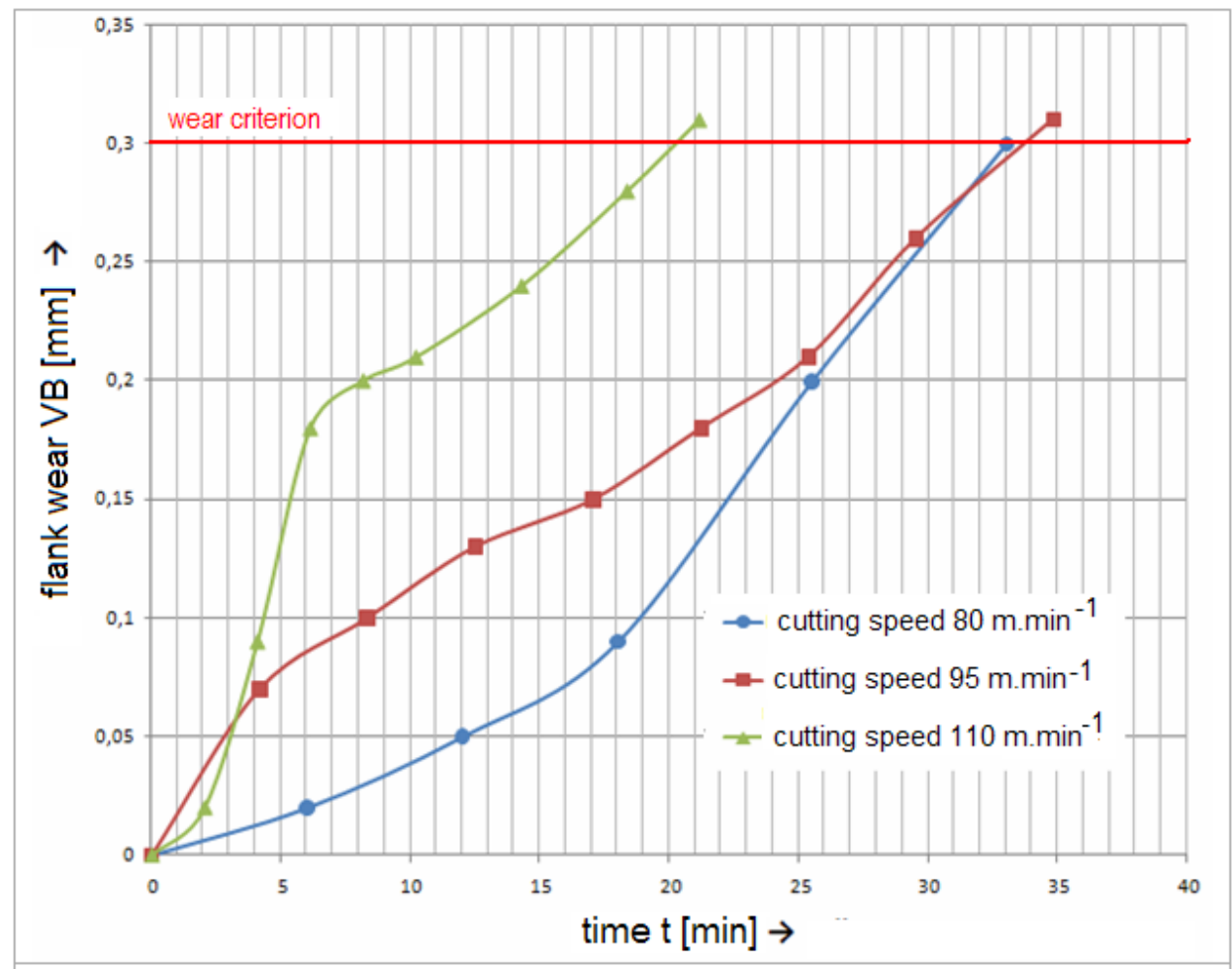

Fig. 6. Cutting speed dependence by function $V B=\mathrm{f}$ (time)
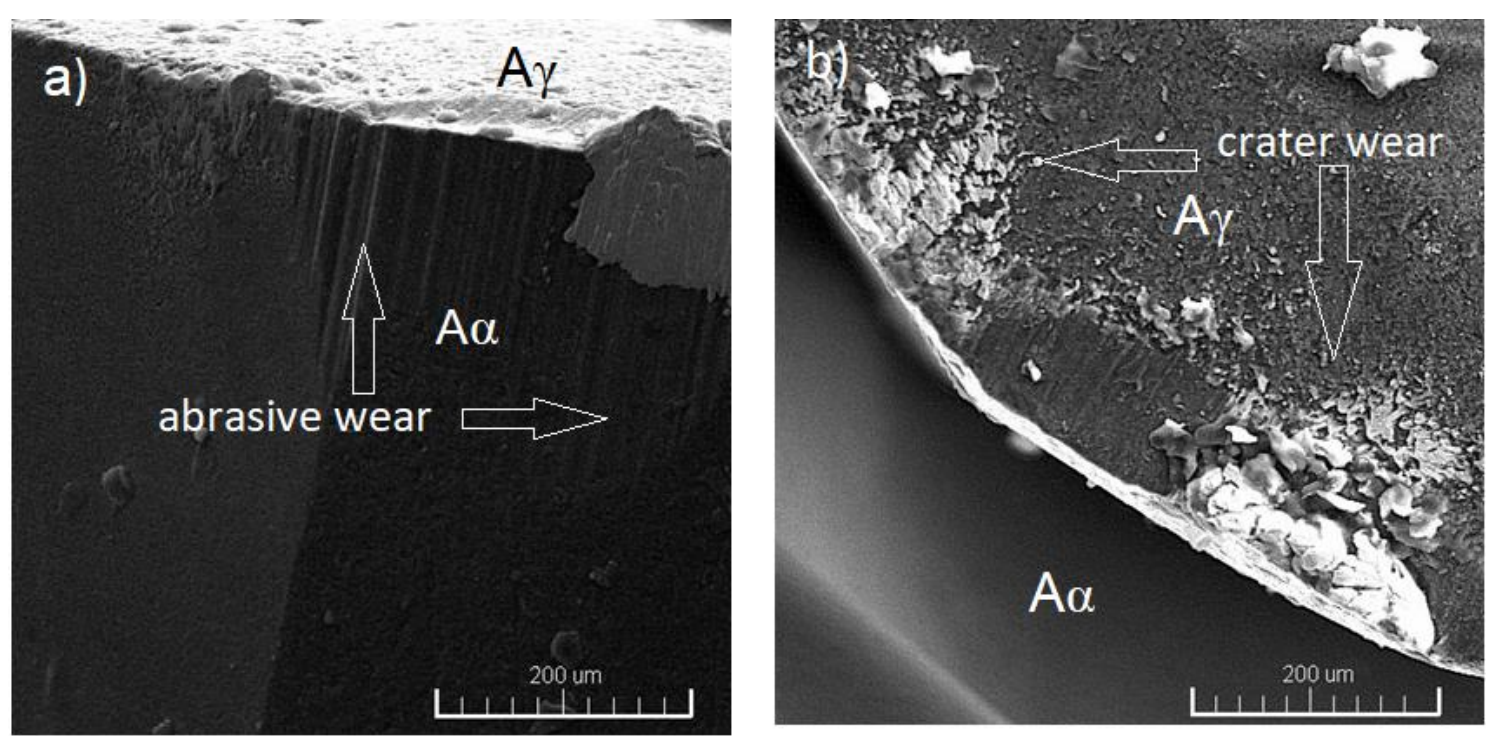

Fig. 7. a) SEM image of flank face A $\alpha$ with mainly observed abrasive wear, b) SEM image of rake face A $\gamma$ of CBN cutting insert with mainly observed crater wear

\section{Conclusion}

By testing the progress of wear of the cutting materials in the form of various studies and experiments with changing cutting parameters, it helps us to better understand the processes occurring in the interaction of the cutting edge with the workpiece. This knowledge leads us to determine certain hypotheses and conclusions that give us the opportunity to further research solve and define subsequent actions leading to a reduction of negative impacts on the structure of the cutting material or on the machining process itself, which ultimately leads to an increase in either cutting performance or tool life. Cubical boron nitride $\mathrm{CBN}$ is currently a cutting material that is the only one that can work hard metal surfaces (with hardness above $50 \mathrm{HRC}$ ) without the need for cutting fluids, which other cutting materials cannot. It is this fact that 
makes it ideal for machining hard surfaces of components. The current trend in mechanical engineering for hard rotating parts is to replace finishing operations by grinding with turning operations, for example using CBN cutting inserts. This trend leads manufacturing companies to more precise products (single-part machining), financial savings in the form of shortening the part-processing time, and also investment savings (as there is no need for grinding equipment). In order to be able to use this cutting material in the most efficient way, including the wear of the cutting edge, it is necessary to know and adhere to certain principles that are specific to this type of material. The purpose of this article was to show in detail the flank wear of the CBN cutting inserts by changing the cutting speed in the form of a real experiment, but also to point out the specifics related to the application of this cutting material.

Current cutting materials still have the possibility to improve them in certain aspects. The simultaneous rivalry between individual cutting tool manufacturers leads to a shift in cutting parameters to higher values, thus increasing their cutting performance. However, the development of wear resistant cutting materials with high cutting parameters is a complex and costly and time consuming process. At present, it is unlikely that new cutting materials will be invented with properties such as cutting edge tool life or a range of applications that would significantly exceed the properties of cutting materials used today. However, by intensive and persistent research and subsequent refinement of existing cutting materials, we can improve their overall properties in the form of increased performance or tool life. The strength and toughness of such materials can be increased not only by reducing the granularity of their hard phases, but also by using various pre-production and manufacturing technologies that help produce high density, low-defect cutting materials. By way of illustration, we can mention the efficient HIP technology (high temperature isostatic pressing) applicable in the production of various types of sintered cutting materials, which achieves significant results. Another trend to improve the properties of current cutting materials is the development of surface coatings for cutting tools and changeable cutting inserts, where the innovations of new types of coatings are effectively increasing the durability of the cutting edge of the tool with defined geometry.

\section{Acknowledgments}

This work was supported by the Slovak Research and Development Agency under the contract No. APVV-15-0710 and also by the BUT, Faculty of Mechanical Engineering, Brno, Specific research 2016, within the grant scheme of "Research of modern production technologies for specific applications", FSI-S-16-3717.

\section{References}

[1] Humár, A. (2008). Materiály pro řezné nástroje - Materials for cutting tools, MM Publishing, ISBN 978-80-2542250-2, Prague

[2] Majerík, J.; Šandora, J. (2012). Nové progresívne nástroje a metódy technológie obrábania - New progressive cutting tools and machining technology methods, J+K, ISBN 978-80-8075-515-7, Trencin

[3] Klocke, F. (2011). Manufacturing Processes 1 Cutting, Springer-Verlag Heidelberg, ISBN 978-3-642-11978-1, Berlin

[4] Cakan, A., Evrendilek, F. \& Ozkaner, V. (2015). Data-driven simulations of flank wear of coated cutting tools in hard turning", Mechanika, Vol. 21, No. 6, 2015, pp. 486-492., ISSN 13921207, DOI 10.5755/j01. mech.21.6.12199

[5] Huang, Y., Chou, Y. K. \& Liang, S. Y. (2007). CBN tool wear in hard turning: A survey on research progresses", International Journal of Advanced Manufacturing Technology, Vol. 35, No. 5-6, 2007, pp. 443-453., ISSN 02683768, DOI 10.1007/s00170-006-0737-6

[6] Pokorný, Z., Dobrocký, D., Kadlec, J. \& Studený, Z. (2018). Influence of alloying elements on gas nitriding process of high-stressed machine parts of weapons", Kovové Materiály - Metallic Materials, Vol. 56, No. 2, 2018, pp. 97103., ISSN 0023432X, DOI 10.4149/km_2018_2_97

[7] Lin, H. M., Liao, Y. S. \& Wei, C. C. (2008).Wear behavior in turning high hardness alloy steel by CBN tool”, Wear, Vol. 264, No. 7-8, 2008, pp. 679-684., ISSN 00431648, DOI 10.1016/j.wear.2007.06.006

[8] Mamalis, A. G., Kundrák, J. \& Horváth, M. (2002). Wear and tool life of CBN cutting tools”, International Journal of Advanced Manufacturing Technology, Vol. 20, No. 7, 2002, pp. 475-479., ISSN 02683768, DOI 10.1007/ s001700200180

[9] Chou, Y. K., Evans, C. J. \& Barash, M. M. (2012). Experimental investigation on CBN turning of hardened AISI 52100 steel", Journal of Materials Processing Technology, Vol. 124, No. 3, 2012, pp. 274-283., ISSN 09240136, DOI 10.1016/S0924-0136(02)00180-2

[10] Poulachon, G., Bandyopadhyay, B. P., Jawahir, I. S., Pheulpin, S. \& Seguin, E. (2004).Wear behavior of CBN tools while turning various hardened steels", Wear, Vol. 256, No. 3-4, 2004, pp. 302-310., ISSN 00431648, DOI 10.1016/S0043-1648(03)00414-9

[11] Dubovská, R.; Jambor, J. \& Majerík, J. (2014). Qualitative aspects of machined surfaces of high strength steels, Procedia Engineering - Proceedings of 24th DAAAM International Symposium on Intelligent Manufacturing and Automation; Zadar, 23 October 2013, Zadar - Croatia, ISSN 18777058, Code 104678, pp. 646-654, Elsevier Ltd, DOI 10.1016/j.proeng.2014.03.038 